\title{
On the Importance of Random Education to Preschool Education
}

\author{
Qisheng Dou, Shouwei Li
}

College of Preschool Education, Zhejiang Normal University, Hangzhou, Zhejiang, China.

Email: 311231 hzxdqs@163.com

Abstract: Because young children are young, their thinking and attention tend to show random characteristics when they are exposed to new things, and they are very vulnerable to the external environment and their own emotions. When children are attracted, their own thinking and awareness will be more active, their language expression will be more vivid, and the quality of learning can be better improved. Therefore, this article explores the specific ways of random education in early childhood education from multiple perspectives, hoping to enable children to achieve better development.

Keywords: Early childhood education; Basic education; Random education; Importance principle

Random education refers to the teaching content that appears outside the teaching plan when the teacher is carrying out the teaching work, and will change according to the teaching situation at the time and the actual learning situation of the students. Because children are young, early childhood education does not place too much emphasis on the systematicness of teaching activities like other education stages, but guides children to learn from all kinds of familiar things in daily life and participating in learning activities. In the process, seize opportunities to educate and guide them, so that children can develop better under the random education of teachers. This requires kindergarten teachers to pay attention to the importance of random education when teaching activities, start with the trivial things in daily life, and find opportunities to effectively carry out random education. This will not only enable young children to effectively link the ubiquitous life scenes with learning content driven by learning interests, but also help young children grow up healthily in a subtle process.

\section{Introducing random education in classroom teaching}

The advantage of random education is that it can break the inherent educational thinking in traditional teaching activities, so that teachers can help children understand knowledge from different angles based on the content that children find randomly. This not only can effectively arouse children's learning enthusiasm, but also can effectively exercise children's thinking consciousness and improve their intellectual level in the process of encouraging them to think continuously. For example, when the author led children to an experimental activity of attracting pins with magnets, many children found it very interesting that the magnets could attract pins. It was a joy to play. But suddenly a child in the class asked me a question: "Teacher, at first, it was obvious that a magnet can suck up pins. Why does this pinned pin become able to attract other pins after it leaves the magnet?" For children's questions, the author does not immediately tell them the answers, but encourages them to observe carefully and think about why the pins become magnetized after being attracted by a magnet. And by leading the children to do experiments, encourage them to solve problems on their own. In this way, children can understand the law of magnetic transfer and attraction in constant discussion. Moreover, in the process of children's discussion with each other, not only the overall learning environment $\underline{\text { is very relaxed, but this kind of randomly discovered problems can better stimulate children's enthusiasm for inquiry, }}$ Copyright (C) 2020 Qisheng Dou et al.

doi: 10.18282/le.v9i5.1249

This is an open-access article distributed under the terms of the Creative Commons Attribution Non-Commercial License

(http://creativecommons.org/licenses/by-nc/4.0/), which permits unrestricted non-commercial use, distribution, and reproduction in any medium, provided the original work is properly cited. 
thereby ensuring the high-quality completion of educational work.

\section{Random education introduced in game activities}

Because children are very young and like to play and play very much, it is often said that it is children's nature to love games. This requires teachers to carefully observe and explore hidden educational opportunities when leading children to participate in game activities, so that children can learn more useful knowledge through participation in game activities. The development of high-quality game activities enables children to actively learn knowledge and mobilize learning enthusiasm in a more relaxed environment. However, it is worthy of teachers' attention that participation in game activities does not mean that children can play freely without any rules. Instead, teachers need to guide children in a targeted manner so that they can gain knowledge and conduct problems through participation in games. The solution. For example, when leading class children to use toys to build houses, I found that some children would arrange their carefully built houses in an orderly manner, but some children would appear too messy when arranging the internal structure of the house. At this time, the author will visit the student's house as a guest, and give proper guidance to the problems in it, so that the children can organize the house in a more orderly manner. This will not only enable children to develop the good habits of diligent use of their brains and good observation, but also the idea of loving cleanliness and tidiness can be introduced into their daily lives, so that children can achieve better development.

\section{Random education}

Random education is very closely related to real life, so when teachers carry out early childhood education, they need to carefully analyze life cases and find the starting point to actively carry out random education in order to enable children to walk, exercise, work, and eat in daily activities., Can learn new knowledge subtly. Real-life education has far-reaching impact on the future development of children. For example, many parents and teachers have been asking children to do about hygiene, but in many cases they only verbally ask children to wash their hands and talk about hygiene, but they rarely do. Teach children the correct way of washing hands. Especially affected by the epidemic now, people are paying more and more attention to personal hygiene, so teachers do a good job of random education in daily life, so that children can actively connect the knowledge they have learned with real life, so as to accumulate more life experience and skills for children At the same time, the children can grow up healthily.

\section{Concluding remarks}

Random education can change the rigidity of traditional teaching content, so that under the guidance of teachers, children can develop learning habits that are good at observing, summarizing and thinking, and can combine the knowledge learned from the daily life to ensure learning The rapid increase in enthusiasm. Since children's thinking consciousness has not yet been developed and perfected, teachers need to pay close attention to children's cognitive level, thinking awareness, and learning characteristics when carrying out educational work. They can start random education with content that children are interested in, so that children can be guided by teachers. Learn more next time. This can not only promote the individualized development of children, but also in the process of mobilizing their learning initiative, so that through the application of thinking ability, the purpose of training children's intelligence level to rise rapidly.

\section{References}

1. Zheng Lijun. How to promote children's understanding of psychological picture books: taking picture book reading "Grandma's Memory" as an example [J]. Scientific Consultation (Educational Research), 2020(06): 171-172.

2. Ma Baolin. The value and significance of children's folk games in early childhood education [C]. Intelligent Learning and Innovation Research Committee of China Intelligent Engineering Research Association. 2020 Education 
Informatization and Education Technology Innovation Academic Forum (Guiyang Venue) Paper Episode (1), 2020: 30-31.

3. Guo Jing. How to cultivate children's self-confidence in early childhood education [C]. China Smart Engineering Research Association Intelligent Learning and Innovation Research Working Committee. 2020 Education Informatization and Education Technology Innovation Academic Forum (Guiyang Venue) Proceedings (3), 2020: $120-121$. 